DOCTRINA

\title{
Términos y condiciones: Acerca del supuesto carácter contractual de las autorizaciones para el tratamiento de datos personales en sitios web
}

\author{
Terms and conditions: About the supposed contractual nature of authorizations \\ for the treatment of personal data on websites
}

\author{
Iñigo DE LA MAZA GAZMURI \\ Universidad Diego Portales, Chile
}

Rodrigo Momberg URIBE

Pontificia Universidad Católica de Valparaíso, Chile

\begin{abstract}
RESUMEN El artículo analiza, en el marco de la contratación electrónica, la supuesta naturaleza contractual de las autorizaciones que dan los usuarios para el uso y tratamiento de sus datos personales. El trabajo plantea que esa autorización únicamente puede considerarse como jurídicamente significativa en la medida en que exista un contrato; cuestión que no siempre acontece, pues no en todos los casos se cumple con los requisitos necesarios para la formación del consentimiento. Al efecto, se examinan especialmente dos recientes sentencias de la Corte Suprema.
\end{abstract}

PALABRAS CLAVE Términos y condiciones, contratos clic, contratos browse, datos personales, privacidad.

ABSTRACT The paper analyses, in the context of electronic contracts, the supposed contractual nature of the authorization that users give for the use and treatment of their personal data. It is asserted that that authorization can only be considered as legally relevant when a contractual relation is present. However, in practice, not in every and any case a contract is concluded, since the conditions for a valid consent by the user can be absent in some. With this purpose, two recent decisions of the Chilean Supreme Court are especially examined.

KEYWORDS Terms and conditions, clickwrap contracts, browsewrap contracts, personal data, privacy. 


\section{Introducción}

Los contratos electrónicos son ubicuos (Kim, 2013: 59) y, probablemente, no haya ninguna exageración cuando, a propósito de ellos, se afirma que celebramos más contratos en un año que nuestros abuelos en toda su vida. ${ }^{1}$ Por otra parte, se ha afirmado que respecto de la formación electrónica del contrato no hay «nada nuevo bajo el sol» (Paz Ares y otros, 2008). Sin perjuicio que algo de cierto puede haber en dicha afirmación, nuestra impresión es que aún no hemos prestado suficiente atención a las particularidades de la contratación electrónica, principalmente aquélla que tiene lugar a través de plataformas como internet.

El tema que nos interesa en este trabajo es la regulación del uso de datos personales a través de documentos disponibles en sitios web que aspiran a disciplinar contractualmente dicho uso. La razón que explica la presencia de estos documentos y su pretendido carácter contractual no es nada de enigmática. El artículo 4 de la Ley 19.628 exige la autorización expresa y por escrito del titular de los datos.

En los casos que presentamos, esa autorización, por así decirlo, se «contractualiza», pues se consigue a través de la voluntad del usuario de aceptar los términos de un supuesto contrato que disciplina el uso del sitio web.

Las hipótesis que deseamos comprobar a través de este trabajo son tres. La primera de ellas es que es una práctica suficientemente difundida, en mercados muy distintos entre sí, que los sitios web soliciten esta autorización contractual para tratar los datos personales de los usuarios. La segunda hipótesis es que esa autorización únicamente puede considerarse como jurídicamente significativa en la medida en que exista un contrato. Nuestra tercera hipótesis es que no en todos los casos puede afirmarse dicha existencia, pues no en todos los casos se cumple con los requisitos necesarios de la formación del consentimiento.

El orden en que procedemos es el siguiente. En primer lugar, procuramos mostrar que la autorización contractual en sitios web para utilizar datos personales se encuentra muy difundida en Chile y que, al considerarla, deben enfrentarse tres preguntas. Mostramos, además, que la primera de ellas (cuya respuesta resulta necesaria para considerar las dos siguientes) es, precisamente, si existe contrato. A continuación, en segundo lugar, mostramos dos recientes sentencias de la Corte Suprema que ilustran, según nos parece, adecuadamente la situación. Nos interesa, en tercer lugar, presentar una diferencia que nos parece relevante respecto a la forma en que se entiende perfeccionado el consentimiento. En cuarto lugar, nos referimos a la forma de estos supuestos contratos y, para hacerlo, advertimos que son electrónicos, por adhesión y que pueden presentarse de dos formas diversas (browse y click). En quinto lugar,

1. Es la afirmación de un columnista del Wall Street Journal, según la cita de Moringiello y Reynolds (2013: 456). 
establecemos los que, en nuestra opinión, deben ser los requisitos de la aceptación frente a estos supuestos contratos. En sexto lugar, equipados con estos requisitos, procedemos a evaluar si en los dos casos resueltos por la Corte Suprema - y en otros semejantes- es posible considerar que exista contrato. Como es usual, cerramos el trabajo con algunas conclusiones.

Por último, debemos aclarar que, en este trabajo, no serán objeto de un análisis detallado las particularidades de la autorización que exige la Ley 19.628 para el tratamiento de datos personales en el marco de la contratación por medios electrónicos. Lo que pretendemos, como se dijo, es resolver una cuestión previa, cual es examinar la naturaleza de las cláusulas o declaraciones mediante las que se pretende obtener la mencionada autorización.

\section{Privacidad por contrato, tres preguntas}

En el ámbito estadounidense se ha señalado que los sitios web han adoptado políticas de privacidad con tal frecuencia que la excepción son aquellos que no lo hacen (Haynes, 2007: 593-594). Aparentemente, Chile presenta la misma situación. Así, aunque sin ninguna pretensión de exhaustividad, es posible encontrar cláusulas de utilización de datos personales en sitios web relacionados con mercados tan disímiles como el retail, la banca, las telecomunicaciones, las redes sociales, los servicios de transporte aéreo y terrestre, medios de prensa y otros.

Aunque resulte tedioso, puede ser útil ilustrar la cuestión con algunas porciones de estas cláusulas.

Por lo que toca al retail, Falabella: ${ }^{2}$

Los datos personales que voluntariamente entregues al hacer uso de este sitio, ingresándolos en el link que se ubica en la parte superior de nuestra página web; o bien al completar un proceso de compra, sólo podrán ser tratados por Falabella Retail para el llenado automático de los documentos, recibos o comprobantes asociados a tus transacciones y para la operación de los medios de pago disponibles en el sitio; no serán entregados a terceros, salvo cuando la ley lo permita, y solo a empresas relacionadas con Falabella Retail en los términos que define el artículo 100 de la Ley 18.045, con fines exclusivamente comerciales. Falabella tendrá disponible, en este sitio, un listado de esas empresas, que podrás consultar, si lo deseas, haciendo click sobre el texto sociedades relacionadas.

Ripley: ${ }^{3}$

Podremos solicitar a los usuarios o clientes información como su nombre, direc-

2. Disponible en http://bit.ly/2ajpaoc.

3. Disponible en http://bit.ly/2iMFhCW. 
ción electrónica, número telefónico, entre otros antecedentes personales. Te aseguramos que estos datos no serán manejados por ninguna empresa que no pertenezca al grupo de empresas Ripley y serán tratados de manera confidencial, conforme a lo establecido por la legislación vigente y exclusivamente utilizados para procesar la compra, el despacho y, en su caso, para el envío de publicidad sobre ofertas y promociones. En los casos que sean comunicados o cedidos a empresas relacionadas a Ripley, se hará con el fin de mejorar la información y comercialización de los productos y servicios distribuidos o prestados.

En lo que corresponde a la banca, Banco del Estado: ${ }^{4}$

Los datos personales que los usuarios, sean personas naturales o jurídicas, proporcionen voluntariamente al Banco a través del portal, serán tratados bajo reserva y sólo para los fines propios del Banco. Posteriormente, siempre que el usuario lo desee y a su requerimiento, los datos personales podrán ser eliminados de la base de datos del Banco.

\section{Corpbanca: ${ }^{5}$}

Para los efectos de la Ley 19.628 Sobre Protección de Datos de Carácter Personal, CorpBanca podrá compartir, con terceros relacionados, asociados y con aquellas entidades a que se encuentre afiliado, datos personales cuando cuente con la autorización expresa del cliente o se dé cumplimiento a las normas legales cuando se trate de información sujeta a reserva o secreto bancario. La utilización de la información, en tale casos, deberá enmarcarse dentro de la finalidad para la cual, el cliente entregó la información.

CorpBanca no podrá vender, traspasar ni comunicar datos de carácter personal de los clientes a terceros distintos de los mencionados anteriormente, sin perjuicio de que los datos personales aportados deberán ser divulgados cuando la ley, organismos del Estado o el poder judicial así lo requieran. No obstante, la autorización otorgada por el cliente puede ser revocada por escrito en cualquier momento.

En lo que se refiere a las telecomunicaciones, Entel: ${ }^{6}$

El usuario y/o cliente autoriza conforme lo indicado en el artículo 4 de la Ley 19.628 el tratamiento de sus datos personales por Entel y sus empresas relacionadas, filiales o matrices con finalidades estadísticas, de marketing, comunicar ofertas y promociones y con el objeto de entregar información y/o beneficios de Entel a los usuarios y clientes. Los referidos datos personales podrán en casos concretos ser comunicados a terceros, para cumplir con las finalidades recién mencionadas.

\footnotetext{
4. Disponible en http://bit.ly/2yYCMnH.

5. Disponible en http://bit.ly/2yXNdFt.

6. Disponible en http://bit.ly/2kOkU5n.
} 
Wom:7

WOM utilizará los datos personales del usuario únicamente para el fin por el cual la información es requerida, informando el propósito y condiciones de entrega de los datos.

WOM no revelará datos personales de sus usuarios, ni los comercializará a terceros, ajenos a WOM y sus empresas relacionadas, salvo que cuente con el consentimiento del usuario.

En el evento de que a los datos capturados se les pudiera dar algún uso diferente al propósito para el cual fueron capturados, WOM informará tal circunstancia al usuario y le entregará la oportunidad de rechazar el uso de sus datos.

Por lo que toca a las redes sociales, Facebook: ${ }^{8}$

En función de los Servicios que utilices, se recopilan diferentes tipos de información relacionada contigo.

Tu actividad y la información que proporcionas. Recopilamos el contenido y otros datos que proporcionas cuando usas nuestros Servicios, como al abrir una cuenta, al crear o compartir contenido y cuando envías mensajes o te comunicas con otros usuarios. La información puede corresponder a datos incluidos en el contenido que proporcionas o relacionados con éste, como el lugar donde se hizo una foto o la fecha de creación de un archivo. También recopilamos información sobre el uso que haces de los Servicios; por ejemplo, el tipo de contenido que ves o con el que interactúas, o la frecuencia y duración de tus actividades.

La actividad de otros usuarios y la información que proporcionan. Asimismo, recopilamos el contenido y la información que otras personas proporcionan cuando usan nuestros Servicios y que puede incluir información sobre ti; por ejemplo, cuando alguien comparte una foto en la que apareces, te envía un mensaje o sube, sincroniza o importa tu información de contacto.

Tus redes y conexiones. Recopilamos información sobre las personas y los grupos a los que estás conectado y cómo interactúas con ellos; por ejemplo, las personas con las que más te comunicas o los grupos con los que te gusta compartir contenido. También recopilamos la información de contacto que proporcionas si subes, sincronizas o importas esta información (por ejemplo, una libreta de direcciones) desde un dispositivo.

Información sobre pagos. Si usas nuestros Servicios para efectuar compras o transacciones financieras (por ejemplo, cuando compras algo en Facebook, realizas una compra en un juego o haces una donación), recopilamos datos sobre la compra o transacción. Esta información incluye tus datos de pago, como tu número de tarjeta de crédito o de débito y otra información sobre la tarjeta, así como otros datos so-

7. Disponible en http://bit.ly/2AoMOSS.

8. Disponible en http://goo.gl/ocKhmz. 
bre la cuenta y sobre autenticación, además de información de facturación, envío y contacto.

Información sobre el dispositivo. Recopilamos información acerca de ordenadores, teléfonos u otros dispositivos donde instales o desde los que accedas a nuestros Servicios, así como la información generada por dichos dispositivos, dependiendo de los permisos que hayas concedido. Podemos asociar la información que recopilamos de tus diferentes dispositivos; de este modo, nos resulta más sencillo prestar Servicios coherentes en todos ellos. Estos son algunos ejemplos de la información de dispositivos que recopilamos:

- Atributos como el sistema operativo, la versión de hardware, la configuración del dispositivo y los nombres y tipos de programas informáticos y archivos, la carga de la batería y la intensidad de la señal, así como datos de identificación del dispositivo.

- Ubicaciones del dispositivo, incluida la posición geográfica específica obtenida, por ejemplo, a través de señales de GPS, Bluetooth o wifi.

- Información sobre la conexión, como el nombre del operador de telefonía móvil o del proveedor de servicios de internet, el tipo de navegador, el idioma y la zona horaria, el número de teléfono móvil y la dirección IP.

Información de sitios web y aplicaciones que utilizan nuestros Servicios. Recopilamos información cuando visitas o utilizas sitios web y aplicaciones de terceros que usan nuestros Servicios (por ejemplo, cuando ofrecen nuestro botón «Me gusta» o el inicio de sesión con Facebook, o cuando usan nuestros servicios de medición y publicidad). Dicha información incluye datos acerca de los sitios web que visitas y las aplicaciones que utilizas, el uso que haces de nuestros Servicios en dichos sitios web y aplicaciones, así como datos que el desarrollador o el editor de la aplicación o del sitio web te proporciona a ti o a nosotros.

Información de socios externos. Recibimos información sobre ti y tus actividades dentro y fuera de Facebook que nos proporcionan socios externos; por ejemplo, información de un socio cuando ofrecemos servicios de forma conjunta o de un anunciante acerca de tus experiencias o interacciones con él.

Empresas de Facebook. Recibimos información acerca de ti que nos proporcionan empresas pertenecientes a Facebook u operadas por Facebook, de conformidad con sus condiciones y políticas. Obtén más información [enlace] acerca de estas empresas y sus políticas de privacidad.

Tinder: ${ }^{9}$

En general. Podremos recopilar Información personal, incluyendo Datos sensibles, y otra información. «Información personal» se entiende como información identificable a nivel individual que nos permitiría determinar la identidad real de una persona en concreto y contactar con ella. El término Datos sensibles incluye información, comentarios o contenido (por ejemplo: fotografías, videos, perfil, estilo de

9. Disponible en http://tinde.rs/2yXSwXS. 
vida) que usted proporcione de forma opcional y que pueda revelar su origen étnico, nacionalidad, religión y/u orientación sexual. Al proporcionarnos Datos sensibles, consiente en la recopilación, uso y divulgación de dichos Datos sensibles en la medida en la que las leyes de privacidad pertinentes lo permitan. También podremos recopilar información de su geolocalización con su consentimiento. Podremos recopilar esta información a través de la página web, de la aplicación móvil o de otros servicios en línea. Al hacer uso del Servicio, nos autoriza a reunir, analizar y conservar datos relacionados con la proporción del Servicio. Cuando proporciona información personal a través del Servicio, la información puede enviarse a servidores situados en los Estados Unidos y en otros países del mundo.

Respecto a servicios de transporte, Latam: ${ }^{10}$

Declaración de Privacidad: Es importante que sepas que Latam Airlines no traspasará, bajo ninguna modalidad y a ninguna empresa que no pertenezca al grupo de empresas de Latam Airlines, datos personales de las operaciones realizadas a través de este sitio web, y te asegura que estos serán manejados en forma absolutamente confidencial y conforme lo dispone la legislación vigente en materia de tratamientos de datos de carácter personal (para Chile Ley 19.628 sobre protección de la vida privada o protección de datos de carácter personal). Lo anterior no obsta a compartir tus datos con aquellas empresas con las que Latam Airlines tenga alianzas o asociaciones comerciales, en la medida que lo hayas autorizado previamente y con el solo objeto de ofrecerte los productos, servicios y beneficios que tengamos para nuestros clientes.

Cabify: ${ }^{11}$

Maxi Mobility recoge datos personales de los Usuarios de la Aplicación y del Sitio Web («Datos Personales») a través de varios medios, como por ejemplo, a través del Formulario de Registro de la Aplicación y del Sitio Web.

Salvo que se indique otra cosa, sin perjuicio de que el suministro de los Datos Personales facilitados a Maxi Mobility es voluntario, la falta de suministro de dichos Datos Personales podrá afectar a la calidad de los servicios proporcionados por Maxi Mobility.

Los Datos Personales de los Usuarios se incluyen en un fichero automatizado de Maxi Mobility con vistas a, entre otros, mantener una adecuada relación con los Usuarios; facilitar el acceso al servicio prestado por Maxi Mobility; prestar, gestionar, administrar, ampliar y mejorar los servicios y/o contenidos ofrecidos en la Aplicación y el Sitio Web; así como para atender adecuadamente cualquier consulta o solicitud de información planteada por los Usuarios y, en su caso, para la remisión de información sobre los servicios o actividades de Maxi Mobility que pudieran ser del interés de los Usuarios.

10. Disponible en http://bit.ly/2ziY6Vt.

11. Disponible en http://bit.ly/2yWWlfY. 
En todo caso, Maxi Mobility declara que los datos personales que registre y procese para el análisis estadístico y anónimo de los tráficos de información, incluso los obtenidos mediante el envío de cookies, serán objeto de un tratamiento automatizado e incorporados a ficheros de su propiedad no accesible a terceros en el momento de la recogida de datos, se solicitará a los Usuarios su consentimiento expreso para que Maxi Mobility pueda hacer uso de sus datos a fin de remitirle información y publicidad por medio de correo electrónico o medios equivalentes, como SMS en teléfonos móviles. Si posteriormente, el Usuario desea revocar su consentimiento otorgado para recibir información comercial vía correo electrónico o por cualquier otro medio similar o equivalente, podrá comunicarlo, enviando un correo electrónico a info@cabify.cl, sin perjuicio de los derechos de acceso, rectificación, cancelación y oposición que le asisten y que podrá ejercitar de conformidad con lo dispuesto en el apartado 6 de la presente Política de Privacidad y Protección de Datos Personales.

\section{Medios de prensa, Emol: ${ }^{12}$}

Los Datos Personales recogidos por la Empresa son objeto de un tratamiento automatizado e incorporados a ficheros de propiedad de la Empresa, que no son accesibles al público. Con todo, la Empresa está facultada para contratar servicios de tratamiento y/o análisis de datos a terceros proveedores.

La Empresa podrá utilizar los Datos Personales para lograr una buena gestión y administración de los Sitios Web, para poder prestar, ampliar y mejorar los servicios que se ofrecen a través de los Sitios Web, para adecuar dichos servicios a las preferencias y gustos de los Usuarios, y para actualizar la información sobre servicios, productos y contenidos ofrecidos por la Empresa o a través de los Sitios Web. La Empresa puede utilizar los Datos Personales para enviar encuestas a los Usuarios, las que los Usuarios no están, sin embargo, obligados a responder.

\section{The Clinic: ${ }^{13}$}

Nuestra política de privacidad describe cómo recogemos, guardamos o utilizamos la información que recabamos a través de los diferentes servicios o páginas disponibles en este sitio. Es importante que entienda qué información recogemos y cómo la utilizamos, ya que el acceso a este sitio implica la aceptación de nuestra política de privacidad.

Aunque existen evidentes diferencias entre estas cláusulas - y las otras de los múltiples documentos que aspiran a disciplinar el uso de los datos personales en el ámbito nacional一, existen también similitudes importantes. En primer lugar, todos los documentos que contienen las cláusulas transcritas pretenden regular contractualmente algo. En segundo lugar, ese «algo» que regulan estos pretendidos contratos es

12. Disponible en http://bit.ly/2iM85vi.

13. Disponible en http://bit.ly/2hnsLq1. 
la prestación de un bien o servicio. En tercer lugar, de manera más directa o más oblicua, la función de todas las cláusulas transcritas - y de tantas otras más- consiste en recabar la autorización para el tratamiento de los datos personales según lo dispuesto en el artículo 4 de la Ley 19.628 sobre Protección de la Vida Privada.

A partir de estas similitudes, resulta posible plantear tres preguntas. La primera es si los documentos que contienen las cláusulas pueden ser considerados como contratos. Si la respuesta a esta primera pregunta es afirmativa, la segunda cuestión consiste en determinar si esa relación contractual se encuentra o no disciplinada por la Ley 19.496 sobre Protección de los Derechos de los Consumidores. Si, nuevamente, se estima que la respuesta es afirmativa, la tercera pregunta es si esas cláusulas resultan o no abusivas.

Al considerar en conjunto las tres preguntas se advierte sin mayor problema la prioridad analítica de las primeras respecto de las consecutivas. De esta manera, no tiene mayor sentido preguntarse si la cláusula resulta o no abusiva según las disposiciones de la Ley 19.496, si antes no se determina la procedencia de la aplicación de dicha ley. Igualmente, no tiene sentido preguntarse si se aplica dicha ley a esta relación contractual, si es que antes no se determina que existe una relación contractual o, en otras palabras, que el documento en el que consta la cláusula de políticas de privacidad puede ser calificado jurídicamente como un contrato.

De esta manera, habrá que concluir que la discusión completa acerca de estas políticas de privacidad que, como se han visto, son ubicuas, reposa, en definitiva, sobre el hecho de que pueda reconocerse carácter contractual al documento que contiene las cláusulas.

Y esta consecuencia parece extraordinariamente importante por dos razones al menos. La primera es que la autorización a que se refiere el artículo 4 de la Ley 19.628 depende de que se le reconozca valor contractual al documento, pues ¿de qué otra manera puede entenderse que el titular de los datos ha entregado su autorización? ${ }^{14}$ De esta manera, si se entiende que aquí no hay contrato, habrá que entender que tampoco hay autorización y que el uso de los datos personales de - literalmente- millones de personas es ilegítimo, pues es sin su autorización y no se encuentra dentro de los supuestos en que la ley permite usar la información sin dicha autorización. ${ }^{15}$ La segunda razón que torna importante la consecuencia a que nos referimos es que,

14. Si bien podría pensarse que la autorización no requiere siempre una relación contractual, para los casos que nos interesan (prestación de bienes y servicios por medio de plataformas electrónicas), siempre la política de privacidad se presenta incluida dentro del marco regulatorio de dicha prestación de bienes o servicios, que tiene (al menos) la pretensión de ser contractual.

15. Como se advirtió, una vez determinada la naturaleza del documento que contiene las cláusulas, se podrán analizar en particular los requisitos de la autorización que requiere el artículo 4 de la Ley 19.628, cuestión que pretendemos dejar, debido a su extensión y complejidad, para un próximo trabajo. 
sorprendentemente, ha pasado desapercibida para la doctrina nacional y para los tribunales superiores de justicia.

Respecto de la doctrina, al menos ninguno de los autores ha sabido encontrar un trabajo que se refiera al tema en el ámbito nacional. Por lo que toca a las sentencias judiciales, hemos encontrado, al menos, dos sentencias de la Corte Suprema sobre cláusulas de políticas de privacidad en estos supuestos contratos; sin embargo, como mostraremos de inmediato, la Corte se ha hecho cargo -inconsistentemente, además- de las preguntas segunda y tercera, es decir, de si se aplica la Ley 19.496 y de si puede o no considerarse abusiva la política de privacidad, sin siquiera considerar la primera pregunta, que es la que posibilita responder las otras dos: ¿puede ser tratado el documento que contiene la cláusula como un contrato?

$\mathrm{Y}$ es, precisamente, esa pregunta la que impulsa este trabajo.

\section{Dos sentencias de la Corte Suprema}

A través de una sentencia de 7 de julio de 2016, la Corte Suprema decidió una demanda colectiva por vulneración del interés difuso incoada por el Servicio Nacional del Consumidor (Sernac) en contra de la empresa Ticketmaster. ${ }^{16}$

En lo que aquí importa, tanto el tribunal de primera instancia como la Corte de Apelaciones de Santiago habían declarado nulas diversas cláusulas. Sin embargo, y esto es lo que interesa directamente a este trabajo, ambos tribunales consideraron que la cláusula «Política de privacidad de Ticketmaster» resultaba válida. Esta decisión fue impugnada a través de un recurso de casación en el fondo por Sernac, reclamando que se había infringido el artículo 16 letra g de la Ley 19.496.

La cláusula en cuestión presentaba el siguiente tenor:

Ticketmaster podrá revelar la información proporcionada por sus Usuarios a terceros, incluyendo patrocinadores, publicistas y/o socioscomerciales. Ticketmaster también recolectará información que es derivada de los gustos, preferencias y en general de la utilización que hacen los Usuarios de los Servicios. Dicha información derivada, al igual que la información personal que los Usuarios proporcionen, podrá ser utilizada para diversos objetivos comerciales, como lo es el proporcionar datos estadísticos (por ejemplo: $50 \%$ de nuestros Usuarios son mujeres) a anunciantes potenciales, enviar publicidad a los Usuarios de acuerdo a sus intereses específicos, conducir investigaciones de mercadeo, y otras actividades o promociones que Ticketmaster considere apropiadas. Ticketmaster también podrá revelar información cuando por mandato de ley y/o de autoridad competente le fuere requerido o por considerar de buena fe que dicha revelación es necesaria para: i) cumplir con procesos legales; ii) cumplir con el Convenio del Usuario; iii) responder reclamaciones

16. Rol 1533-2015. 
que involucren cualquier Contenido que menoscabe derechos de terceros o; iv) proteger los derechos, la propiedad, o la seguridad de Ticketmaster, sus Usuarios y el público en general.

A partir del considerando undécimo de la sentencia, la Corte Suprema desarrolla argumentos para justificar el carácter abusivo de la cláusula en cuestión, tanto con cargo a la Ley 19.496 como acudiendo a la Ley 19.628, con lo cual concluye que infringe la letra g del artículo $16 \mathrm{y}$, por lo tanto, la priva de eficacia. Al comienzo de dicha argumentación, la Corte indica lo siguiente:

Esta cláusula contiene diversas autorizaciones a Ticketmaster. No son sin embargo autorizaciones que el usuario dé positiva y especialmente. Tampoco son autorizaciones supletorias que el usuario pueda denegar si así lo desea. Son autorizaciones que se entienden concedidas por el consumidor por el solo hecho de usar el sitio. Esta característica resultará determinante para establecer el carácter abusivo de buena parte de estas autorizaciones.

La segunda sentencia que nos interesa considerar, del 6 de diciembre de 2016, ${ }^{17}$ resuelve un caso que vuelve a enfrentar al Servicio Nacional del Consumidor con una empresa dedicada a la venta de entradas para eventos, Ticketek. El contenido de la cláusula que esta vez importa es el siguiente:

Al utilizar estos servicios, el titular de datos personales presta su consentimiento conforme a lo establecido en la Ley 19.628 para transmitir, comunicar y poner a disposición de filiales, sociedades de apoyo al giro y sociedades relacionadas a Ticketek, nacionales o extranjeras, sus datos personales e información, que hubiera entregado a Ticketek o que ésta haya obtenido de acuerdo a sus procedimientos de registro y procedimientos internos, otorgando autorización expresa para el tratamiento automatizado de dichos datos e información y su utilización para servicios actuales o futuros que desarrolle Ticketek.

La Corte Suprema, conociendo de un recurso de casación en el fondo, señaló respecto de esta cláusula que el debate debía centrarse en la legitimación que tendría el Sernac para demandar, por medio de una acción de defensa del interés difuso de los consumidores, la nulidad de la mencionada clausula. Al efecto, la Corte destaca que la Ley 19.628 contiene procedimientos especiales, por lo que, sumado a la definición de datos personales del artículo 2 letra $\mathrm{f}$,

es posible extraer que la ley de datos de carácter personal regula una cuestión esencialmente individual, desde que protege a cada persona cuya información pueda estar en poder y ser administrada por los titulares de bancos de datos, quien asume

17. Rol 26.932-2015. 
una posición propia sobre su tenencia y uso, que puede motivar la necesidad que sean modificados o eliminados, o no merecer reparos. Por tal motivo es que la ley regula un procedimiento que nace del interés individual, que inicialmente se manifiesta en el requerimiento hecho al poseedor de los datos y que no necesariamente derivará en un pleito de carácter judicial. Esto deja en evidencia que no es posible asumir que la ley especial pueda ceder ante la general, aún en el caso de procedimientos de interés colectivo o difuso de los consumidores, puesto que la naturaleza de los asuntos regulados por la Ley 19.628 es esencialmente individual, sin que tengan cabida los procesos colectivos.

Consideradas en conjunto estas dos sentencias, descubrimos dos cosas que resultan útiles a efectos del propósito que impulsa este trabajo. Y, todavía, añadiremos otra que ha de animar un trabajo posterior.

Lo primero que advertimos es que en ambos casos de trata de una situación en que existe un documento que aspira a regular contractualmente un determinado bien o servicio que se ofrece a través de un sitio web. Ese servicio puede ser, en estos casos, la venta de entradas, pero también el uso del sitio a través del cual es posible adquirir las entradas.

Lo segundo que descubrimos es que, en ambas sentencias, la discusión acerca de si existía o no un contrato brilla por su ausencia. ${ }^{18} \mathrm{Y}$ es cierto que, para decirlo metafóricamente, los tribunales responden a las preguntas que les hacen las partes, pero también resulta bastante evidente que si no existe contrato, y eso es evidente de la lectura de los antecedentes allegados por las partes, el tribunal debe advertir que el problema no es, como en la primera sentencia, el carácter abusivo de la cláusula o, como en el segundo, el ámbito de aplicación de la Ley 19.496, sino, precisamente, la inexistencia del contrato.

En fin, lo tercero que percibimos al comparar estas sentencias es algo de lo que nos ocuparemos en un trabajo posterior, pero que conviene dejar, al menos, señalado aquí, y es la inconsistencia de ambas sentencias.

Para comprender esto último, podemos volver a nuestras tres preguntas y recordar que únicamente tiene sentido responder a la pregunta acerca del carácter abusivo o no de la cláusula de privacidad si resulta ser cierto el hecho de que se debe aplicar la Ley 19.496.

Pues bien, así las cosas, no quedará sino advertir que la primera sentencia de la Corte Suprema - la del 7 de julio de 2016 - asume que en el caso se aplica la Ley 19.496. ¿De qué otra manera podría explicarse que emplee sus preceptos? Por su par-

18. Si bien la Corte Suprema, en el considerando undécimo de la sentencia del caso Ticketmaster, hace referencia a una «condición general de la contratación», presupone que dicha condición general se inserta en las relaciones contractuales entre Ticketmaster y los consumidores, sin cuestionar si efectivamente hay o no contrato por el mero uso del sitio del proveedor. 
te, frente a un caso perfectamente equivalente en términos jurídicos, la Corte, cinco meses después, en la segunda sentencia -6 de diciembre de 2016-, falla exactamente lo contrario. ${ }^{19}$

Pues bien, como ha quedado dicho ya, esta tercera cuestión deberá esperar. Nuestra atención ahora debe centrarse en si es posible o no entender que había contrato en estos casos, y con esta finalidad, hemos de apuntar una diferencia relevante en lo que se refiere a la formación del consentimiento en ambas situaciones.

\section{Una diferencia respecto a la formación del consentimiento entre Ticketmaster y Ticketek}

Para comprender esta diferencia, convendrá comenzar recordando la argumentación de la Corte Suprema en la primera sentencia, la del 7 de julio de 2016. Allí se sostiene lo siguiente:

Esta cláusula contiene diversas autorizaciones a Ticketmaster. No son sin embargo autorizaciones que el usuario dé positiva y especialmente. Tampoco son autorizaciones supletorias que el usuario pueda denegar si así lo desea. Son autorizaciones que se entienden concedidas por el consumidor por el solo hecho de usar el sitio. Esta característica resultará determinante para establecer el carácter abusivo de buena parte de estas autorizaciones.

19. La contradicción de la Corte es más clara aún si se analiza la sentencia de casación de fecha 11 de octubre de 2016 ( $R o l$ 4903-2015, Sernac con Créditos Organización y Finanzas S.A.). Si bien el caso no trataba sobre cláusulas de privacidad, sino sobre cláusulas relativas a la inclusión de deudores morosos en el Boletín Comercial, la relación entre la Ley 19.496 y la Ley 19.628 fue discutida expresamente. En dicha causa, la demandada alegó la improcedencia de la acción colectiva deducida en su contra, ya que, a su juicio, el uso y tratamiento de datos personales no podía ser objeto de un procedimiento de interés colectivo, considerando especialmente que la propia Ley 19.628 establece un procedimiento especial de reclamo e indemnización. Según la demandada, se trataría entonces de una materia regulada por una ley especial que excluye la aplicación de la Ley 19.496 en los términos del artículo 2 bis de dicho cuerpo legal. La Corte Suprema desechó estas alegaciones, y luego de referirse a la ampliación de la protección a los consumidores que significó la introducción de las acciones supraindividuales, señaló que «si bien el tratamiento de datos personales está regulado en una ley especial, la afectación de intereses supraindividuales que implica la contratación en situación de desigualdad mediante contratos de adhesión, cuyo contenido acarrea el desequilibrio entre las partes que se refleja, entre otros, en el quebrantamiento de los derechos de los titulares de datos de carácter personal, constituye una materia susceptible de ser conocida en esta sede. Más clara es esta inferencia cuando se advierte que el proceso judicial de la ley de protección a la vida privada está previsto únicamente para el resguardo de un interés individual, mientras que el de estos antecedentes se refiere al interés colectivo de todos aquellos deudores que suscribieron el informativo convenio con la expectativa no cumplida de ser eliminados del Boletín Comercial, de manera que nos encontramos en el caso previsto en la letra b del artículo 2 bis de la Ley 19.496, ya que si bien las normas de protección al consumidor no son aplicables, en principio, en materia de datos personales, sí lo son cuando se compromete el interés colectivo o difuso». 
A continuación, habrá que recordar la segunda sentencia - la del 6 de diciembre de 2016- y la cláusula de políticas de privacidad. Su contenido es el que sigue:

$\mathrm{Al}$ utilizar estos servicios, el titular de datos personales presta su consentimiento conforme a lo establecido en la Ley 19.628 para transmitir, comunicar y poner a disposición de filiales, sociedades de apoyo al giro y sociedades relacionadas a Ticketek, nacionales o extranjeras, sus datos personales e información, que hubiera entregado a Ticketek o que ésta haya obtenido de acuerdo a sus procedimientos de registro y procedimientos internos, otorgando autorización expresa para el tratamiento automatizado de dichos datos e información y su utilización para servicios actuales o futuros que desarrolle Ticketek.

En el caso de Ticketmaster, la Corte tuvo por establecido que la autorización del titular para el uso de sus datos se entendía concedida por el solo uso del sitio. La Corte, correctamente, llega a esa conclusión, ya que al revisar la cláusula primera («Condiciones de uso») de los términos y condiciones de Ticketmaster, se lee:

Bienvenido a Ticketmaster. A continuación se describen las Condiciones de Uso (En adelante las «Condiciones») que rigen el uso del sitio Web de Ticketmaster.cl (en adelante, el «Sitio»). Al usar o visitar el Sitio, el usuario expresamente manifiesta su conformidad y se obliga con los términos y condiciones de esta página.

Por otra parte, según la cláusula del caso Ticketek, la autorización se entiende concedida «al utilizar estos servicios», es decir, por el solo hecho de utilizar estos servicios. Cuáles sean esos servicios, no es algo que se indique en la cláusula; habrá que entender que son aquellos que es posible utilizar a través de la página.

¿Cuál es, entonces, la diferencia entre ambos casos? La respuesta, en nuestra opinión, exige prestar atención al proceso de venta de entradas por parte de Ticketek. Y, al hacerlo, se descubre que el proceso de venta de las entradas pasa por una serie de pasos en los que, en primer lugar, es necesario suministrar abundantes datos personales incluyendo el RUT, fecha de nacimiento, género, domicilio, teléfono fijo, móvil y correo electrónico. Esto, sin considerar la información necesaria para cursar los pagos. De esta manera, el usuario queda registrado en el sitio. Luego de eso, justo antes de concluir con el proceso de compra, luego de haber elegido el evento y la ubicación exacta, aparece la siguiente leyenda:

Sr. Cliente, para continuar el proceso de compra de tickets, debe aceptar las condiciones indicadas en la sección Términos y Condiciones de nuestra página. Acepto las Políticas de Venta y Devolución de Entradas.

La expresión «Términos y Condiciones» se encuentra vinculada a otra parte del sitio web; si se pincha sobre ella, el usuario es dirigido a un documento que se denomina «Términos y Condiciones». 
Pues bien, la diferencia debería resultar relativamente obvia: en Ticketmaster se pretende que el documento, los términos y condiciones, resulta vinculante por el solo hecho de visitar el sitio web. En Ticketek, en cambio, se pretende que el documento sea vinculante a través de un acto afirmativo que consiste en indicar expresamente que se aceptan los «Términos y Condiciones». ${ }^{20}$

Para no perder de vista lo que nos interesa en este trabajo, convendrá advertir que esta diferencia puede o no ser jurídicamente relevante según la importancia que tenga para determinar la existencia de un contrato. Y lo que muestra tanto Ticketmaster como Ticketek es que esto va a depender de si el usuario aceptó los términos y condiciones. ${ }^{21}$

Nos parece, sin embargo, que la cuestión exige un tratamiento más moroso respecto de la forma de los contratos electrónicos. Eso es lo que nos ocupa en la próxima sección de este trabajo.

\section{La forma de los contratos}

\section{El carácter electrónico de los contratos}

Ante todo, en lo que se refiere a la forma, nos encontramos frente a contratos electrónicos, consideración importante en esta sección, pues el criterio para calificar un contrato como electrónico es, precisamente, la forma en que se celebra, que es lo mismo que la manera en que se entiende formado el consentimiento.

La regulación de este tipo de contratos en Chile es más bien escuálida. En primer lugar, existe una mención, críptica para el profano, acerca de qué debe entenderse por electrónico en la Ley 19.799 sobre documentos electrónicos, firma electrónica y servicios de certificación de dicha firma. Se trata de la letra a del artículo 2. Su tenor es el siguiente: «Electrónico: característica de la tecnología que tiene capacidades eléctricas, digitales, magnéticas, inalámbricas, ópticas, electromagnéticas u otras similares». En segundo lugar, en la letra d del mismo artículo se define documento electrónico como: «Toda representación de un hecho, imagen o idea que sea creada, enviada, comunicada o recibida por medios electrónicos y almacenada de un modo idóneo para permitir su uso posterior.» A continuación, en tercer lugar, el artículo 3 de la Ley establece lo que podría denominarse el "principio de equivalencia», cuyo inciso primero dispone:

20. Refuerza lo dicho la circunstancia que en el título denominado «Nuestras Políticas», se señala «Cuando compres tus boletos a través del sistema Ticketek, por favor asegúrate de conocer las siguientes políticas...» (el destacado es nuestro).

21. Cabe sí precisar que una cuestión distinta será determinar si se han cumplido las condiciones para la autorización a que se refiere el artículo 4 de la Ley 19.628. 
Los actos y contratos otorgados o celebrados por personas naturales o jurídicas, suscritos por medio de firma electrónica, serán válidos de la misma manera y producirán los mismos efectos que los celebrados por escrito y en soporte de papel. Dichos actos y contratos se reputarán como escritos, en los casos en que la ley exija que los mismos consten de ese modo, y en todos aquellos casos en que la ley prevea consecuencias jurídicas cuando constan igualmente por escrito.

En fin, en cuarto lugar, la Ley 19.496 se refiere a ellos en algunas disposiciones; ${ }^{22}$ sin embargo, más allá de caracterizarlos como una especie de contratos celebrados a distancia, no los define.

No existe, entonces, definición del contrato electrónico en el derecho nacional. A pesar de ello, el juego de las disposiciones de la Ley 19.799 permite definirlos de la misma forma en que lo ha hecho en España la letra h del Anexo de la Ley 34/2002, de 11 de julio, de Servicios de la Sociedad de la Información y del Comercio Electrónico, es decir, como «todo contrato en el que la oferta y la aceptación se transmiten por medio de equipos electrónicos de tratamiento y almacenamiento de datos, conectados a una red de telecomunicaciones».

\section{Contratos por adhesión}

La segunda consideración relevante en este tipo de contratos electrónicos es que, como lo muestran todos los ejemplos que se han empleado hasta aquí, la forma que asumen los documentos que disciplinan el uso de los datos personales por parte de quien los recolecta es la adhesión. Es decir, se trata de contratos de adhesión en el sentido que da el artículo 1 número 6 de la Ley del Consumidor, es decir: «Aquel cuyas cláusulas han sido propuestas unilateralmente por el proveedor sin que el consumidor, para celebrarlo, pueda alterar su contenido». ${ }^{23}$

Existe, aún, una tercera consideración que ha de tenerse en cuenta respecto a la forma en que se presentan estos contratos por adhesión que determina que el énfasis deba ser distinto al que, por lo general, se da a los contratos por adhesión.

Tradicionalmente, tratándose de los contratos de adhesión, el énfasis ha estado puesto en el carácter abusivo o no de sus cláusulas (De la Maza y Cruz, 2003). En los documentos que aquí nos interesan, el énfasis, en primer lugar al menos, está en si puede o no asignársele carácter contractual, pues resulta perfectamente posible que la

22. Así, por ejemplo, el artículo 3 bis letra b se refiere al retracto tratándose de los contratos celebrados por medios electrónicos; el artículo 12.a se refiere a la formación del consentimiento en esta especie de negocios; el artículo 32 se refiere a la información que debe suministrar el proveedor cuando ofrezca la celebración de contratos electrónicos; finalmente, el artículo 50 se refiere a la competencia de los juzgados de policía local tratándose de contratos electrónicos.

23. Sobre este tipo de contratos, véase De la Maza y Cruz (2003). 
persona que, supuestamente, acepta sus términos y condiciones ni siquiera sospeche la existencia del pretendido contrato (Mann y Siebeneicher, 2008: 986; Livingston, 2011: 603).

Conviene desarrollar esta idea.

Si bien la problemática tradicional de los contratos por adhesión tiene ya más de un siglo (De la Maza y Cruz, 2003), la que venimos examinando ahora tiene menos de tres décadas. Así, por ejemplo, si se presta atención al ámbito estadounidense, que es donde estas cuestiones se han desarrollado de manera más intensa, lo que podríamos considerar algo así como el neandertal de los contratos por adhesión electrónicos - los shrinkwraps contracts $-{ }^{24}$ no parece ser anterior a la década de los noventa del siglo pasado, y el caso que suele citarse como el precursor directo de la aceptación judicial de los contratos por adhesión electrónicos - ProCD Inc. con Zeidenberg- ${ }^{25}$ es de 1996.

Lo que allí se discutió, a propósito de la regulación de una licencia software que únicamente resultaba visible una vez que comenzaba a utilizarse el programa, fue precisamente si ese documento podía considerarse como un contrato de licencia, si al momento de adquirir el CD que lo contenía, el comprador no tenía acceso a los términos de dicha licencia. Sin embargo, en la caja que contenía el CD aparecía una advertencia acerca de la existencia de la licencia. El tribunal que resolvió el caso decidió que constituía un contrato y, por lo tanto, el contenido de la licencia obligaba al comprador.

Los desarrollos de ProCD respecto a la formación del consentimiento pavimentaron el camino para que, luego, se aceptara que se había formado el consentimiento $-\mathrm{y}$, por lo tanto, había contrato- en situaciones en las que, en el interior de un sitio web, existe un documento - frecuentemente denominado «términos y condiciones»— que aspira a disciplinar contractualmente el uso de la página o la adquisición de bienes y servicios que resulta posible a través de ella.

La cuestión que se ha suscitado respecto del carácter contractual de los términos y condiciones se refiere a la formación del consentimiento y, en lo que nos interesa de inmediato, más específicamente a la aceptación de dichos términos y condiciones por parte de los usuarios.

Un par de ejemplos contribuirán a ilustrar cómo se manifiestan estos problemas.

El primero de ellos corresponde a Caspi con Microsoft Network, LLC. ${ }^{26}$ Los hechos fueron los siguientes: Steven Caspi y muchos otros usuarios demandaron a Microsoft por incumplimiento de contrato y fraude respecto de un contrato en virtud del cual se les suministraba un servicio de mensajería instantánea, disciplinado por un

\footnotetext{
24. Sobre ellos, puede consultarse Kim (2013: 36-39).

25. 86 F.3d 1447 (7th Cir. 1996).

26. 732 a.2d 528 (NJ Super. 1999).
} 
contrato que permitía a Microsoft aumentarles unilateralmente el costo cada vez que modificaba el plan del servicio. La defensa de Microsoft consistió en afirmar que el tribunal que estaba conociendo de la disputa carecía de competencia para hacerlo, pues la cláusula 15.1 del acuerdo de membresía MSN disponía lo siguiente: «This agreement is governed by the laws of the State of Washington, USA, and you consent to the exclusive jurisdiction and venue of courts in King County, Washington in all disputes arising out of or relating to your use of MSN or your MSN membership». ${ }^{27}$

El tribunal que conoció el caso indicó que, para acceder al servicio de mensajería de Microsoft, la persona debía, previamente, utilizar un determinado sitio web que sucesivamente lo iba guiando a través de una serie de documentos en los cuales se indicaba claramente la presencia del acuerdo de membresía y se ofrecía al usuario la posibilidad de aceptar sus términos o de negarse a ellos. La única forma de acceder al servicio, por supuesto, consistía en aceptar dicho acuerdo.

Consideró el tribunal que al aceptar (al hacer clic sobre el recuadro que indicaba «I Agree») el acuerdo de membresía, el usuario, a la vez, había aceptado la cláusula de prórroga de competencia y, por lo mismo, ésta le resultaba oponible. Los usuarios habían cliqueado su aceptación y de esta manera se había formado un «contrato clic» (click-wrap contract).

El segundo ejemplo corresponde a Specht con Netscape Communications Corp. ${ }^{28}$ El demandado ofrecía en su sitio web un programa de software -Netscape Smart Download - en forma gratuita a quienes deseasen descargarlo a sus computadores. Además de la función explícita del software - bajar documentos en forma más eficiente-, éste cumplía una segunda tarea: enviar información sobre los documentos bajados a Netscape. Para bajar el programa a su computador el usuario únicamente debía pulsar el ícono de bajada (download) y éste comenzaba a descargarse. Si el usuario se desplazaba hacia el extremo inferior de la página descubría un enlace que contenía un aviso redactado en los siguientes términos: «Por favor revise y acepte los términos del software NSD antes de descargarlo y utilizarlo». Este texto contenía un enlace que transportaba al usuario a una página separada titulada «License and Support Agreements» que notificaba al usuario que todos los productos de Netscape se encontraban regulados por contratos de licencias que debían ser aceptados por los usuarios antes de comenzar a utilizarlos. Esta página contenía además un nuevo enlace que transportaba al usuario al contrato de licencia de NSD, el cual, según su texto, vinculaba al usuario a sus términos por el solo hecho de bajar el programa.

Los demandantes argumentaron que al recabar información sobre los archivos

27. «Este acuerdo se rige por las leyes del estado de Washington, Estados Unidos, y usted consiente a la jurisdicción exclusiva y domicilio de los tribunales del condado de King, Washington, en todas las disputas surgidas por o relacionadas con su uso de MSN o su membresía de MSN».

28. 306 F.3d 17, Segundo Circuito, 2002. 
que bajaban, Netscape infringía su derecho a la privacidad espiando ilegalmente sus comunicaciones. Netscape se defendió argumentando que la licencia que regulaba la utilización del producto prorrogaba la competencia para conocer de los asuntos contenciosos a un tribunal arbitral ubicado en el condado de Santa Clara, California. En lo que interesa, la Corte debió resolver si dicha cláusula formaba parte de un contrato que vinculase a las partes. La Corte consideró que no.

Los argumentos de la Corte fueron básicamente que del hecho de seleccionar un ícono titulado «descarga» (download) no podía desprenderse la aceptación por parte de los usuarios de los términos del contrato de licencia que regulaba la utilización de NSD. En palabras de la Corte:

No estamos de acuerdo con la afirmación de que un usuario razonablemente prudente en la posición del demandante habría conocido necesariamente o sabido con certeza acerca de la existencia del contrato de licencia de SmartDownload antes de actuar, de manera que pueda considerarse que el demandante ha prestado su aceptación al contrato con noticia suficiente de sus términos.

Junto a lo anterior, la Corte advirtió que si bien los demás productos de Netscape se encontraban regulados por contratos de licencia, éstos eran presentados a los usuarios en una forma distinta, que aseguraba, al menos, que los usuarios tuviesen oportunidad de revisar los términos del contrato si así lo deseaban y que condicionaba el uso del producto a la aceptación de dichos términos, lo que no ocurría en este caso. Por estas razones, la Corte decidió que la cláusula de prórroga de la competencia no vinculaba al demandante.

A esta segunda forma que pueden asumir los contratos electrónicos se le denomina «contrato browse» (browse-wrap contract) y, como ha sugerido Kim, su peculiaridad radica en que no se requiere que los usuarios manifiesten afirmativamente su aceptación; de hecho - continúa la autora-, resulta frecuente que se trate de un hipervínculo en el sitio web que indica la existencia de los términos y condiciones, que se entienden aprobados por el solo uso del sitio (Kim, 2013: 41). Lo relevante es que el usuario no requiere acceder al hipervínculo ni realizar ninguna otra manifestación expresa para que se entienda obligado por los términos predispuestos por el proveedor, bastando el mero uso o visita (browse) del sitio web.

Confirmando lo resuelto en Specht con Netscape Communications Corp., la jurisprudencia estadounidense se ha inclinado por negar validez a estos contratos si el usuario no ha tenido noticia previa suficiente de la existencia de sus términos. ${ }^{29} \mathrm{En}$ este sentido, una sentencia reciente, Nguyen con Barnes and Noble, ${ }^{30}$ declaró, a propósito de una venta en línea, que las cláusulas contenidas en los «Terms of use» de

29. Véase Kim (2013) y Trakman (2009), ambos con extensa referencia a la jurisprudencia.

30. Inc 12-566628, 2014 WL 4056549, Noveno Circuito, 18 de agosto de 2014. 
la página web del vendedor no obligaban al adquirente si tales cláusulas eran sólo posibles de conocer a través del acceso a un hipervínculo, operación que el usuario no estaba obligado a realizar para completar la transacción.

En el mismo sentido se ha pronunciado la Corte de Justicia de la Unión Europea en Content Services Ltd con Bundesarbeitskammer. ${ }^{31}$ El caso se refería a la exigibilidad de una cláusula de renuncia al derecho de retracto, contenida en las condiciones generales de venta del proveedor. Para acceder a los servicios, el consumidor debía rellenar un formulario de inscripción y declarar que aceptaba las condiciones generales de venta marcando una casilla designada en el formulario, sin lo cual no era posible acceder a los servicios. El usuario podía acceder a las condiciones generales por medio de un enlace disponible en la misma página del formulario de inscripción. La Corte estimó que la cláusula de renuncia al retracto no cumplía con los requisitos de la entonces vigente Directiva $97 / 7$ sobre contratos a distancia, y por tanto no podía entenderse incorporada al contrato, ya que

una práctica comercial que consiste en dar acceso a la información prevista en esta disposición sólo mediante un hipervínculo a un sitio de internet de la empresa en cuestión no cumple lo exigido por dicha disposición, ya que tal información no es ni «facilitada» por esa empresa ni «recibida» por el consumidor, en el sentido de esta misma disposición, y un sitio de internet como del que se trata en el litigio principal no puede considerarse un «soporte duradero» (considerando 51).

Por otra parte, los contratos clic se caracterizan porque requieren del usuario una acción positiva de manifestación de consentimiento para acceder a los servicios ofrecidos por el proveedor a través de la página web. Esta acción consiste habitualmente en pulsar o «hacer clic» en un botón, cuadro de diálogo o casilla que contiene la palabra «Acepto» u otra expresión similar (De la Maza, 2007; Kim, 2013). La presentación de los términos propuestos por el proveedor puede realizarse por medio de su despliegue en una ventana o página separada, o por el acceso a un enlace. En todo caso, lo esencial del contrato clic es que requiere una acción positiva por parte del usuario, la cual es condición para que se complete la transacción. Esta es la diferencia fundamental con los contratos browse, los cuales no requieren manifestación alguna por parte del usuario respecto a los términos que propone el proveedor, que simplemente se encuentran disponibles vía uno o más enlaces, pero sin que el usuario requiera acceder a ellos o realizar alguna acción positiva para completar la transacción y utilizar los servicios.

La regla general en derecho comparado es que se acepte la validez de los contratos clic y por tanto el usuario resulte obligado por sus términos (Macdonald, 2011; Trakman, 2009; Kim, 2013). Así, por ejemplo, en Scherillo con Dun \& Bradstreet, aun cuando los términos del contrato se presentaban al usuario en una ventana separada,

31. Sentencia C-49/11, del 5 julio de 2012. 
que era necesario desplazar verticalmente para poder leer las condiciones ofrecidas, el tribunal decidió que tales términos eran exigibles, ya que no era posible para el usuario concluir la transacción sin hacer clic en la casilla «Acepto», lo cual implicaba una manifestación expresa de consentimiento..$^{32}$

Ahora bien, la nitidez de la distinción entre contratos clic y contratos browse y la precisión descriptiva de cada una de estas expresiones no debe exagerarse. Como ha sido sugerido, las expresiones "contrato clic» $\mathrm{y}$ "contrato browse» pueden emplearse cada una para describir fenómenos muy diversos entre sí que merecen tratarse de una forma diversa (Moringiello y Reynolds, 2013: 466-467).

No obstante esta justa crítica, considerar la distinción presta alguna utilidad para efectos de este trabajo. De una parte, muestra que el problema aquí no es, exactamente, respecto del carácter abusivo de las cláusulas, sino de la existencia misma del contrato. En segundo lugar, aparece que ese problema aquí se ha tematizado a través de la aceptación de los términos y condiciones del documento que se pretende como contrato. En tercer lugar, con respecto a la aceptación, la cuestión parece girar, parcialmente al menos, en torno al acceso que tenga el usuario al contenido de los términos y condiciones.

\section{Los dos requisitos de la aceptación}

Todo indica que Ticketmaster - y los demás documentos que aquí hemos considerado-pertenece a la más pura cepa de contratos browse, pues, como se recordará, el contrato se entiende celebrado por el solo hecho de visitar el sitio. En cambio, Ticketek aparece como un contrato clic.

Y siendo de esta manera, puede aceptarse como hipótesis que, tal y como ha sucedido en el ámbito estadounidense, lo relevante sea determinar si existió o no aceptación y, a la vez, precisar si existió aceptación pasa por definir si el usuario tuvo - y en qué condiciones- acceso a los términos y condiciones.

Esta hipótesis puede comprobarse, parcialmente al menos, de inmediato acudiendo al artículo 12.a de la Ley 19.496. Su texto es el siguiente:

En los contratos celebrados por medios electrónicos, y en aquéllos en que se aceptare una oferta realizada a través de catálogos, avisos o cualquiera otra forma de comunicación a distancia, el consentimiento no se entenderá formado si el consumidor no ha tenido previamente un acceso claro, comprensible e inequívoco de las condiciones generales del mismo y la posibilidad de almacenarlos o imprimirlos.

La sola visita del sitio de internet en el cual se ofrece el acceso a determinados servicios, no impone al consumidor obligación alguna, a menos que haya aceptado en forma inequívoca las condiciones ofrecidas por el proveedor.

32. 684 F.Supp. 2d 313 [E.D.N.Y. 2010]. 
Una vez perfeccionado el contrato, el proveedor estará obligado a enviar confirmación escrita del mismo. Esta podrá ser enviada por vía electrónica o por cualquier medio de comunicación que garantice el debido y oportuno conocimiento del consumidor, el que se le indicará previamente. Dicha confirmación deberá contener una copia íntegra, clara y legible del contrato.

Algo semejante parece desprenderse del inciso segundo del artículo 32 de la Ley 19.496, según el cual:

Tratándose de contratos ofrecidos por medios electrónicos o de aquellos en que se aceptare una oferta realizada a través de catálogos, avisos o cualquier otra forma de comunicación a distancia, el proveedor deberá informar, de manera inequívoca y fácilmente accesible, los pasos que deben seguirse para celebrarlos, e informará, cuando corresponda, si el documento electrónico en que se formalice el contrato será archivado y si éste será accesible al consumidor. Indicará, además, su dirección de correo postal o electrónico y los medios técnicos que pone a disposición del consumidor para identificar y corregir errores en el envío o en sus datos.

Ahora bien, afirmamos que la hipótesis únicamente queda parcialmente acreditada, pues, como ya ha quedado dicho, las sentencias que hemos considerado de la Corte Suprema no permiten afirmar, categóricamente, que en estos casos se aplique la Ley 19.496.

Sin embargo, lo que nos interesa defender aquí es que, aun cuando se considerara que dicha ley no se aplica, lo dispuesto en los incisos primero y segundo del artículo 12.a y el inciso segundo del artículo 32 sí que recibiría aplicación. No, desde luego, porque se encuentre en estos preceptos, sino más bien porque esos preceptos plasman en la Ley 19.496 algo que debe entenderse como una idea general en el derecho de contratos y es que la aceptación exige, al menos en términos generales, ${ }^{33}$ los dos requisitos a que refieren los incisos primero y segundo del primer precepto. Por otra parte, la accesibilidad a los términos del contrato y la manifestación inequívoca de la aceptación exigen que el oferente suministre la información a que se refiere el inciso segundo del artículo 32.

El primero de los requisitos es que la persona a quien se le atribuye la aceptación haya tenido la posibilidad de acceder al contenido del documento que se quiere hacer valer como contrato. El segundo de los requisitos consiste en que aquella conducta a la que se da el valor de aceptación resulte, en ese sentido, suficientemente indubitada.

El primero de los dos requisitos no parece haber llamado mayormente la aten-

33. Es decir, despojado de peculiaridades propias de la Ley 19.496 como la exigencia que formula el inciso primero del artículo 12.a respecto de la posibilidad de almacenar e imprimir el texto de los términos y condiciones. 
ción de la doctrina nacional ${ }^{34} \mathrm{y}$, en algún sentido, resulta razonable; después de todo, ¿cómo podría aceptarse aquello a lo que no se ha tenido acceso? Una respuesta posible es - como lo entendió el juez Frank Easterbrook en ProCD - como una asunción de riesgo, en términos tales que lo que se le informa al usuario es que existen unos determinados términos y condiciones, pero no se le da acceso a éstos hasta que ha celebrado el contrato. Esta es una posibilidad, pero no resulta interesante para casos como los que se están considerando aquí. La razón es que los contratos shrinkwrap, en los que tiene lugar esta modalidad de "pague primero y lea después», no tienen ninguna justificación en el mundo de los contratos electrónicos. En el mundo, digamos, de los contratos papel, la tiene porque el documento que contiene el contrato se encuentra en el interior del envoltorio en el cual se encuentra el bien.

¿Qué justificación posible podría existir para que en un sitio web no se encontraran disponibles los términos y condiciones que, entre otras cosas, disciplinan el uso del sitio? La respuesta, por supuesto, es ninguna.

El segundo requisito consiste en que se haya manifestado inequívocamente el consentimiento. A diferencia del anterior, sobre este requisito se ha debatido extensamente en el derecho civil, y con mayor intensidad respecto a las manifestaciones de voluntad tácita y el valor del silencio, con énfasis en las relaciones de consumo (Momberg, 2014). Por lo que toca a la primera, generalmente, puede afirmarse que suele reconocérsele el mismo valor que a la expresa, siempre y cuando se desprenda inequívocamente de los hechos a los que se pretende asignar este valor (Claro Solar, 2015: 98). Con respecto al silencio, la regla general es que no se le asigna el valor de aceptación (Claro Solar, 2015: 99).

Como ya ha quedado dicho, la regulación de los contratos electrónicos en el derecho chileno es particularmente escueta, ya que se limita, en lo que a formación del consentimiento se refiere, a un par de artículos - el 12.a y el 32 inciso segundo- de la Ley 19.496. Sin embargo, un vistazo a otros ordenamientos jurídicos que se han hecho cargo de la cuestión en términos más generales debería indicar que tanto el acceso a los términos y condiciones como el carácter inequívoco de la conducta a la cual se da el valor de aceptación, y que haya información suficiente sobre estas dos cosas, son requisitos necesarios para que se entienda formado el contrato.

De esta manera, una mirada al ámbito estadounidense muestra que en el 2007 la American Bar Association promulgó una serie de recomendaciones en calidad de buenas prácticas para la contratación electrónica, e identificó cuatro directivas básicas acerca de la formación del consentimiento (Terenzi, 2010: 1.079-1.080). La primera de ellas es que el usuario debe tener una notificación adecuada acerca de la existencia de los términos y condiciones. La segunda consiste en que el usuario debe

34. Así, por ejemplo, no es considerada por Claro Solar (2015), León Hurtado (1979), Domínguez Águila (2012) ni por Vial del Río (2000). 
tener una oportunidad significativa de examinar esos términos y condiciones. A continuación, la tercera directiva consiste en que el usuario debe recibir una notificación adecuada de que realizar ciertas conductas equivale a manifestar la aceptación de los términos y condiciones. Finalmente, en cuarto lugar, el usuario, de hecho, debe incurrir en esas conductas.

Por otra parte, si se considera el ámbito europeo, el análisis de estas materias se ha relacionado con el denominado principio de transparencia, de acuerdo con el cual el proveedor debe asegurar a la otra parte la oportunidad para conocer los términos del contrato antes de su celebración, debiendo tales términos estar redactados de tal forma que puedan ser entendidos por el consumidor promedio (Loos, 2015).

Este principio ha sido consagrado en diversos instrumentos legislativos. Así, la Directiva 93/13/ECC sobre cláusulas abusivas señala en su considerando veinte que los contratos deben redactarse en términos claros y comprensibles y que el consumidor debe contar con la posibilidad real de tener conocimiento de todas las cláusulas, lo cual es confirmado por el artículo 5 del mismo instrumento, que establece que «en los casos de contratos en que todas las cláusulas propuestas al consumidor o algunas de ellas consten por escrito, estas cláusulas deberán estar redactadas siempre de forma clara y comprensible.» También, el artículo 10 de la Directiva 2000/31/EC sobre comercio electrónico exige que el prestador de servicios facilite de manera clara, comprensible e inequívoca, antes que el destinatario del servicio efectúe un pedido, la información relevante, como, por ejemplo, los diferentes pasos técnicos que deben darse para celebrar el contrato, añadiendo que las condiciones generales de los contratos deben estar disponibles de tal manera que el destinatario pueda almacenarlas y distribuirlas. Asimismo, el reciente Reglamento 2016/79 del Parlamento Europeo y del Consejo sobre protección de las personas físicas en lo que respecta al tratamiento de datos personales, reconoce expresamente en sus considerandos el principio de transparencia, lo cual se manifiesta en particular en las normas sobre consentimiento y los derechos del interesado relativos al tratamiento de sus datos personales..$^{35}$

35. El artículo 7.2 señala: «Si el consentimiento del interesado se da en el contexto de una declaración escrita que también se refiera a otros asuntos, la solicitud de consentimiento se presentará de tal forma que se distinga claramente de los demás asuntos, de forma inteligible y de fácil acceso y utilizando un lenguaje claro y sencillo. No será vinculante ninguna parte de la declaración que constituya infracción del presente Reglamento». Por su parte, el artículo 12.1, bajo el título «Transparencia de la información, comunicación y modalidades de ejercicio de los derechos del interesado», prescribe que «el responsable del tratamiento tomará las medidas oportunas para facilitar al interesado toda información indicada en los artículos 13 y 14, así como cualquier comunicación con arreglo a los artículos 15 a 22 y 34 relativa al tratamiento, en forma concisa, transparente, inteligible y de fácil acceso, con un lenguaje claro y sencillo, en particular cualquier información dirigida específicamente a un niño. La información será facilitada por escrito o por otros medios, inclusive, si procede, por medios electrónicos. Cuando lo solicite el interesado, la información podrá facilitarse verbalmente siempre que se demuestre la identidad del interesado por otros medios». 
Es interesante destacar que también la fallida Propuesta de la Comisión Europea de Normativa Común de Compraventa Europea (CESL) incluye en sus disposiciones normas sobre transparencia. Así, el artículo 70 establece el deber de llamar la atención sobre las cláusulas contractuales no negociadas individualmente, disponiendo que:

1) Las cláusulas contractuales impuestas por una de las partes y no negociadas individualmente a tenor del artículo 7 podrán ser invocadas contra la otra parte sólo si esta tuvo conocimiento de ellas, o si la parte que las impuso adoptó las medidas razonables para que la otra parte tuviera conocimiento de ellas antes de la celebración del contrato o durante dicha celebración. 2) A efectos del presente artículo, en las relaciones entre un comerciante y un consumidor, la mera referencia en el texto del contrato no bastará para considerar que se han adoptado medidas suficientes para que el consumidor tenga conocimiento de las cláusulas contractuales, aun cuando el consumidor haya suscrito el documento.

El artículo 82 impone asimismo el deber de transparencia en las cláusulas contractuales no negociadas individualmente, estableciendo que: «Cuando un comerciante incorpore cláusulas contractuales que no hayan sido negociadas individualmente con el consumidor a tenor del artículo 7 , tendrá el deber de asegurarse de que se redacten y comuniquen en un lenguaje sencillo y comprensible». ${ }^{36}$

La CJUE se ha pronunciado en diversas ocasiones respecto al contenido y extensión del principio de transparencia. Así, en RWE con Verbraucherzentrale Nordrhein-Westfalen, ${ }^{37}$ la Corte señaló que el deber de transparencia a que están sujetos los contratos de adhesión no se satisface por la mera referencia, en las condiciones generales o cláusulas tipo, a disposiciones legales o reglamentarias que puedan aplicarse al contrato, sino que es esencial que el consumidor sea informado del contenido de las disposiciones de que se trate, de manera de resguardar el interés legítimo del consumidor de conocer y prever las consecuencias de la aplicación de dichas disposiciones. En el mismo sentido, en Kásler con OTP Jelzálogbank ${ }^{38}$ la Corte señaló que la exigencia de transparencia de las cláusulas contractuales establecida por la Directiva 93/13 no puede reducirse sólo al carácter comprensible de éstas en un plano formal y gramatical, de manera que un consumidor medio esté no sólo al tanto de la existencia de los términos del contrato, sino que sea capaz de evaluar las consecuencias económicas y jurídicas de la aplicación y cumplimiento de los mismos.

En definitiva, en el contexto de este trabajo, lo que cabe resaltar es que el deber de transparencia implica más que la mera disponibilidad de la información, pues es esencial

36. Otros instrumentos de derecho uniforme también contienen normas relativas al principio de transparencia: artículo 2:104 PECL, y artículos II.- 9:103, II.- 9:402 y II.- 3:105 DCFR.

37. Sentencia C-92/11, 26 de abril de 2013.

38. Sentencia C-26/13, 30 de abril de 2014. Véase también Hatóság con Invitel, sentencia C-472/10, 26 de abril de 2012. 
que el destinatario conozca dicha información y pueda entenderla, de manera de prever los efectos del contrato y por tanto decidir si acepta o no los términos que se le proponen.

Explicada la situación en el derecho comparado, si volvemos a los requisitos mencionados para la formación del contrato (que la persona a quien se le imputa la aceptación haya tenido la posibilidad de acceder al contenido del documento que se quiere hacer valer como contrato, y que aquella conducta a la que se da el valor de aceptación resulte, en ese sentido, suficientemente indubitada) y se acepta que estos dos requisitos resultan aplicables en general a la formación del contrato, la siguiente tarea consiste en determinar si es que pueden entenderse cumplidos en los casos de Ticketmaster y Ticketek.

\section{Ticketmaster y Ticketek revisitados}

Asumiendo que la Corte Suprema lleva razón cuando señala en su sentencia de 6 de julio de 2016 - la de Ticketmaster - que las supuestas autorizaciones de los usuarios «se entienden concedidas por el consumidor por el solo hecho de usar el sitio», entonces no queda sino asumir que el documento en el que se encuentran las políticas de privacidad corresponde a lo que hemos denominado un «contrato browse». Y la pregunta es si la forma en que se ofrece ese documento satisface los requisitos para considerarlo jurídicamente como un contrato.

Como ya lo hemos dicho, es el ámbito estadounidense donde la cuestión se ha discutido con mayor intensidad. Señalamos, además, que en Specht con Netscape Communications Corp. ${ }^{39}$ se decidió que el documento ofrecido por Netscape carecía de carácter contractual, pues no se le ofreció al usuario una oportunidad razonable de conocer el contenido de dicho documento, y, por lo mismo, no puede asumirse que haya aceptado sus términos. Sin embargo, en otros casos, en los cuales el documento no aparece en el sitio web, sino que lo que hay es un hipervínculo que conduce a él, se ha decidido que existe contrato..$^{40} \mathrm{La}$ diferencia entre los casos en que se reconoce el carácter contractual y aquellos en que no, parece encontrarse en que el usuario haya tenido suficiente noticia acerca de la existencia del contrato; y la tendrá cuando: i) recibe una comunicación indicándole que debe cesar en ciertos actos, pues suponen una infracción contractual (pero se considerará que hay contrato únicamente a partir del momento en que recibida la notificación, el usuario siga utilizando el bien o servicio) o bien, ii) cuando en el sitio web existe un hipervínculo presentado de manera suficientemente conspicua que permita al usuario comprender que allí existe un contrato (Kim, 2013: 107).

39. Véase la nota 29.

40. Así, por ejemplo, en Register.com, Inc. con Verio, Inc., 356 F.3d 393, Segundo Circuto, 2004, y en Hubbert con Dell Corp., 835 N.E. 2 d 113 (Ill: App. 5 Dist. 2005). 
¿Existe un contrato en Ticketmaster y en otros casos similares? ${ }^{41}$ Convendrá recordar la relevancia de esta pregunta. Si se asume que no son contratos, entonces, a la vez, ha de asumirse que no existe autorización del usuario para la utilización de sus datos personales, y el uso de ellos contraviene lo dispuesto en la Ley 19.628, lo que posibilita, entre otras cosas, una demanda civil por daño moral. Y la respuesta - al menos siguiendo los razonamientos de los tribunales estadounidenses- tendría que ser que ello depende de si el consumidor tuvo suficiente acceso al contenido del contrato y se le informó sobre a qué conducta se le daba el valor de manifestación de voluntad.

En el caso de Ticketmaster, la respuesta a la segunda cuestión es sencilla: se le daba valor de aceptación de los términos y condiciones al solo hecho de utilizar el sitio. La segunda cuestión - ¿tuvo acceso el usuario al contenido de los términos y condiciones? - resulta más complicada. Y resulta más complicada porque para saberlo sería necesario examinar el sitio web y comprobar de qué manera se presentaba el hipervínculo que conducía a los términos y condiciones. Desgraciadamente -al menos para estos efectos-, la empresa Ticketmaster abandonó Chile el año 2012 y no es posible ahora revisar su sitio web. Sin embargo, algunas cuestiones deberían resultar suficientemente obvias. Si la existencia de un contrato se informa a través de un hipervínculo, es una carga del oferente el que no exista duda acerca de la existencia del contrato y esto supone, en primer lugar, que el hipervínculo debe estar ubicado en un lugar prominente de la página que se está visitando, lo que significa que no puede estar semioculto al final de dicha página. En segundo lugar, que el tamaño de la fuente que utiliza no sea inferior al de los otros contenidos de la página. En tercer lugar, que el color de la fuente sea tal que no termine confundiéndose con el fondo de la página y, en cuarto lugar, que la expresión que se emplea en el hipervínculo resulte suficientemente indiciaria de la existencia de un contrato. ${ }^{42}$

Un ejemplo servirá para ilustrar lo dicho. The Clinic ${ }^{43}$ tiene en su página de inicio un hipervínculo denominado «Política de Privacidad»;44 al pulsarlo, aparece un documento que se denomina «Política de privacidad de The Clinic», cuyo primer párrafo es el siguiente:

Nuestra política de privacidad describe cómo recogemos, guardamos o utilizamos la información que recabamos a través de los diferentes servicios o páginas disponibles en este sitio. Es importante que entienda qué información recogemos y cómo la utilizamos, ya que el acceso a este sitio implica la aceptación de nuestra política de privacidad.

41. Sólo a modo de ejemplo, y sin ninguna pretensión de exhaustividad: Google (http://bit.ly/2ymSKs6), Youtube (http://bit.ly/1uhYtr5), Tripadvisor (http://bit.ly/2z5RDuo), Easy (http://bit.ly/2iSzzPS), Groupon (http://bit.ly/2ylZBSA) y Emol (http://bit.ly/2iM85vi).

42. Sobre estos cuatro requisitos, véase De la Maza y Cruz (2003).

43. Disponible en http://www.theclinic.cl/.

44. Disponible en http://bit.ly/2hnsLq1. 
«El acceso a este sitio implica la aceptación de nuestra política de privacidad». Se trata, entonces, de lo que hemos denominado un «contrato browse» y lo que aspira a disciplinar, entre otras cosas, es el uso de datos personales. ¿Satisface los requisitos para que se lo considere como un contrato? Nuestra opinión es que no. De los cuatro requisitos que hemos establecido, considerando las cosas con buena voluntad, creemos que satisface solamente uno. En primer lugar, se encuentra hacia el final de la página, de manera que al momento de ingresar al sitio es perfectamente invisible. En segundo lugar, el tamaño de la fuente es notablemente inferior a la de los otros contenidos de la página. En tercer lugar, su color es gris oscuro contra un fondo negro. Acaso lo único en que cumpla es que se denomina «Política de privacidad».45

De esta manera los términos y condiciones presentes en The Clinic - y en otros sitios similares, como los que se han indicado- $-{ }^{46}$ no satisfacen ninguno de los dos requisitos para que pueda considerárseles como contratos. En primer lugar, no se ofrece un acceso claro a ellos, y como la indicación de qué conductas constituyen aceptación se encuentra en los propios términos y condiciones, tampoco puede estimarse que se informe al usuario al respecto.

Es ahora el momento de considerar Ticketek. Y se trata, a simple vista al menos, de un caso distinto a Ticketmaster. En este último no existían problemas para considerar el documento ofrecido como un contrato browse. En el primero, en cambio, no parecen existir problemas para considerarlo como un contrato clic. ¿Satisface esta forma de presentar el documento los requisitos necesarios para entender que aquí existe un contrato?

La respuesta en nuestra opinión es que, al menos en principio, sí. ${ }^{47}$ La razón es que antes de que se entienda perfeccionado el contrato de compraventa, el usuario es informado acerca de la existencia de los términos y condiciones y su carácter contractual en forma suficientemente conspicua, y se le indica que su aceptación constituye un requisito indispensable para continuar adelante con el proceso de compra.

De esta manera, creemos, el usuario no podría alegar, con posterioridad, que ignoraba la existencia de los términos y condiciones, o que al pulsar «Acepto» no estaba manifestando una voluntad contractual.

Cuestión distinta, por supuesto, es que pueda alegar que el contenido de estos términos y condiciones es abusivo. Para eso deberá ser el caso, en primer lugar, que se aplique la Ley 19.496 y, en segundo lugar, que la política de privacidad sea susceptible

45. Lo cual tampoco asegura que, para un usuario razonable, ello se identifique con un contrato.

46. Véase la nota 42.

47. Una respuesta más definitiva exigiría considerar el funcionamiento completo del sitio y determinar si todos los bienes y servicios que pueden adquirirse a través de él se encuentran disciplinados por este contrato clic o si, en cambio, para acceder a otros igualmente hay que entregar datos personales sin que se pida aceptar expresamente los términos y condiciones que disciplinan el uso de los datos personales. 
de subsumirse en alguna de las hipótesis de cláusulas abusivas del artículo 16 letra g de aquella ley. Estas dos cuestiones deberían ser el objeto de dos trabajos posteriores.

\section{Conclusión}

Como en cualquier trabajo en el que se formulen hipótesis, la conclusión debe dar cuenta del destino de éstas. Convendrá comenzar recordándolas. La primera de ellas es que es una práctica suficientemente difundida en mercados muy distintos entre sí que los sitios web soliciten esta autorización contractual para tratar los datos personales de los usuarios. La segunda hipótesis es que esa autorización sólo puede considerarse como jurídicamente significativa en la medida en que exista un contrato. Nuestra tercera hipótesis es que no en todos los casos puede afirmarse dicha existencia, pues no en todos los casos se cumple con los requisitos necesarios de la formación del consentimiento.

Creemos haber mostrado en las primeras páginas de este trabajo lo extraordinariamente difundido que se encuentra en diversos mercados, en el ámbito nacional, el uso de términos y condiciones que aspiran a disciplinar de forma contractual el uso de datos personales por parte de quien los recaba.

En segundo lugar, en la medida en que se acepte que esos términos y condiciones aspiran a regular contractualmente el uso de los sitios web o de los bienes y servicios que se pueden adquirir a través de ellos, habrá que asumir, a la vez, que la licitud del uso de los datos, dependerá, al menos, ${ }^{48}$ del hecho de que, en efecto, se haya perfeccionado un contrato. En otras palabras, creemos haber demostrado que la autorización para usar los datos coincide con la aceptación que forma el contrato por lo general denominado «términos y condiciones».

Finamente, nos parece que hemos probado que no en todos los casos de términos y condiciones resulta posible afirmar que se ha formado un contrato - ello es especialmente cierto en los denominados «contratos browse»- $y$, por lo tanto, no se puede asumir que el titular de los datos haya dado su aceptación para el uso de los mismos. De esta manera, no queda más que asumir que en todos esos casos el uso de los datos es ilegal.

\section{Referencias}

Claro Solar, Luis (2015). Explicaciones de derecho civil chileno y comparado. T. 11. Santiago: Editorial Jurídica de Chile.

De la MAZA, Iñigo (2007). «Justicia contractual, contratos de adhesión electrónicos

48. Decimos «al menos» porque, según ya hemos indicado, existen requisitos en la Ley 19.628 que no hemos considerado en este trabajo, reservándolos para uno próximo. 
y buena fe». En Hernán Corral y María Rodríguez (editores), Estudios de derecho civil II. Santiago: LexisNexis.

De la MAza, Iñigo y Sergio Cruz (2003). "Contratos por adhesión y plataformas electrónicas». Alfa Redi: Revista de Derecho Informático, 117: 1-50. Disponible en http://bit.ly/2zGUlJ3.

Domínguez Águila, Ramón (2012). Teoría general del negocio jurídico. Santiago: Editorial Jurídica de Chile.

HaYNES, Allison (2007). «Online privacy policies: Contracting away control over personal information?». Pennsylvania State Law Review, 111: 587-624.

KIM, Nancy (2013). Wrap contracts. Foundations and ramifications. Oxford: Oxford University Press.

León Hurtado, Avelino (1979). La voluntad y la capacidad en los actos jurídicos. Santiago: Editorial Jurídica de Chile.

LIVINGSTON, Jared (2011). «Invasion contracts: The privacy implications of terms of use agreements in the online social media setting». Albany Journal for Science and Technology, 21 (3): 591-636. Disponible en http://bit.ly/2imRNVU.

Loos, Marco (2015). "Transparency of standard terms under the Unfair Contract Terms Directive and the proposal for a common European sales law». European Review of Private Law, 23 (2): 179-193. Disponible en http://bit.ly/2xKyUm4.

MACDONALD, Elizabeth (2011). "When is a contract formed by the browse-wrap process?». International Journal of Law and Information Technology, 19 (4): 285-305. DOI: 10.1093/ijlit/earoo9.

ManN, Ronald y Travis Siebeneicher (2008). «Just one click: The reality of internet retail contracting». Columbia Law Review, 108 (4): 984-1.012. Disponible en http:// bit.ly/2gYv2HE.

MOMBERG, Rodrigo (2014). «Las cláusulas de modificación unilateral en las relaciones de consumo». En Francisca Barrientos (coordinadora), Condiciones generales de la contratación y cláusulas abusivas. Santiago: Ediciones Universidad Diego Portales.

Moringiello, Julliet y William Reynolds (2013). «From Lord Coke to internet privacy: The past, present, and future of the law of electronic contracting». Maryland Law Review, 72 (2): 452-500. Disponible en http://bit.ly/2gUAyuN.

Paz-Ares Rodríguez, Cándido, Nuria Gutiérrez Bermejo y María Isabel Sáez LACAVE (2008). «La formación electrónica del contrato: Nada nuevo bajo el sol». En José Manuel Sala Arquer y Julián Martínez-Simancas (coordinadores), Derecho sobre internet. Madrid: Banco Santander Central Hispano.

TerenzI, Robert (2010). «Friending privacy: Toward self-regulation of second generation social networks». Fordham Intellectual Property, Media and Entertainment Law Journal, 20 (3): 1.049-1.106. Disponible en http://bit.ly/2z5YqGm.

Trakman, Leon (2009). "The boundaries of Contract Law in cyberspace». Public Contract Law Journal, 38 (1): 187-236. Disponible en http://bit.ly/2h3MmyH. 
VIAL DEL Río, Víctor (2000). Teoría general del acto jurídico. Santiago: Ediciones de la Universidad Católica de Chile.

\section{Reconocimiento}

Este trabajo presenta resultados del proyecto Fondecyt regular 1170983 (años 20172018), titulado: «Las cláusulas para el uso y tratamiento de datos personales en la contratación por medios electrónicos. Un análisis desde el derecho de contratos», cuyo investigador responsable es Rodrigo Momberg Uribe, y su coinvestigador es Íñigo de la Maza Gazmuri.

\section{Sobre los autores}

IÑIgo de la Maza Gazmuri es abogado. Doctor en Derecho, profesor de Derecho Civil e investigador en la Facultad de Derecho de la Universidad Diego Portales. Su correo electrónico es inigo.delamaza@udp.cl.

Rodrigo Momberg Uribe es abogado. PhD de la Universidad de Utrecht. Profesor de Derecho Civil de la Pontificia Universidad Católica de Valparaíso. Su correo electrónico es rodrigo.momberg@pucv.cl. 


\title{
REVISTA CHILENA DE DERECHO Y TECNOLOGÍA
}

La Revista de Chilena de Derecho y Tecnología es una publicación académica semestral del Centro de Estudios en Derecho Informático de la Facultad de Derecho de la Universidad de Chile, que tiene por objeto difundir en la comunidad jurídica los elementos necesarios para analizar y comprender los alcances y efectos que el desarrollo tecnológico y cultural han producido en la sociedad, especialmente su impacto en la ciencia jurídica.

\author{
EDITOR GENERAL \\ Daniel Álvarez Valenzuela \\ (dalvarez@derecho.uchile.cl) \\ SITIO WEB \\ rchdt.uchile.cl \\ CORREO ELECTRÓNICO \\ rchdt@derecho.uchile.cl \\ LICENCIA DE ESTE ARTÍ́CULO \\ Creative Commons Atribución Compartir Igual 4.0 Internacional
}

\begin{abstract}
y
La edición de textos, el diseño editorial

y la conversión a formatos electrónicos de este artículo

estuvieron a cargo de Tipográfica

(www.tipografica.cl).
\end{abstract}

